\title{
PENGUKURAN PANJANG DAN BOBOT IKAN GABUS (Channa striata) DI SUNGAI MUSI, SUMATERA SELATAN
}

\author{
Mirna Dwirastina \\ Teknisi Litkayasa pada Balai Riset Perikanan Perairan Umum, Mariana-Palembang
}

Teregristasi I tanggal: 20 Pebruari 2006; Diterima setelah perbaikan tanggal: 10 Mei 2006; Disetujui terbit tanggal: 27 Maret 2007

\section{PENDAHULUAN}

Perairan umum merupakan bagian permukaan bumi yang secara permanen atau berkala tertutup oleh masa air dan terbentuk secara alami berupa air tawar misalnya sungai, danau, maupun berupa air payau yang bersifat umum (Wibowo \& Sunarno, 2005). Menurut Peraturan Pemerintah No.35 tahun 1991 pasal 1 sungai adalah tempat-tempat dan wadah serta jaringan pengaliran air mulai dari mata air sampai dengan muara sungai dengan dibatasi kanan dan kiri serta sepanjang pengaliran oleh garis sempadan.

Wilayah Sumatera Selatan meliputi 2,5 juta ha perairan umum berupa sungai yang dikenal dengan Sungai Musi (Wibowo \& Sunarno, 2005). Sungai Musi merupakan sungai terpanjang di Indonesia, dengan panjang sekitar $700 \mathrm{~km}$ (Anonimus, 1987). Menurut Wibowo \& Sunarno (2005) bahwa sumber air Sungai Musi berasal dari pegunungan bukit barisan dan Danau Ranau yang mengalir ke arah timur melewati Kota Palembang dan selanjutnya bermuara di Selat Bangka.

Daerah tangkapan di daerah aliran Sungai Musi mencakup luasan $60.000 \mathrm{~km}^{2}$ (Gaffar, 2003). Pada daerah tangkapan tersebut dijumpai jenis-jenis ikan misal toman, lais, sapil, tembakang, gabus, dan lainlain.

Ikan gabus merupakan salah satu ikan yang sering ditemukan pada saat penangkapan dan bernilai ekonomis penting. Bentuk tubuh panjang, silindris, sirip anus, dan sirip punggung panjang serta lunak, warna corak coklat (Hoeve, 1996). Dikenal masyarakat dalam bentuk segar maupun bentuk olahan.

Penelitian tentang ikan gabus telah banyak dilakukan antara lain biologi reproduksi serta pakan (Makmur, S. et al., 2003 ). Ikan gabus mempunyai ukuran bermacam-macam dengan variasi bobot yang juga beragam. Karena itu, pengambilan data pengukuran panjang dan bobot sangat perlu dilakukan. Pengamatan data panjang dan bobot ikan yang benar akan mempengaruhi hasil penelitian tersebut. Pengukuran panjang dan bobot ikan dalam biologi perikanan mengacu pada ketentuan yang digunakan, yaitu pengukuran panjang dapat diukur menggunakan sistem metrik sedangkan pengukuran bobot dengan menggunakan timbangan (Effendie, 1975).

\section{HASIL DAN BAHASAN}

\section{Alat Pengukuran}

\section{Mistar atau Papan Ukur}

Pengukuran panjang ikan gabus dapat menggunakan papan ukur (Gambar 1). Bila pengukuran contoh awal adalah panjang total, maka pengukuran contoh berikut dimulai juga dari panjang total. Setelah pengukuran panjang total baru diteruskan mengukur panjang standar. Demikian juga, dasar satuan yang digunakan harus tetap dalam penelitian agar data akurat dan tidak terjadi kesalahan, apabila satuan centi meter $(\mathrm{cm})$, maka seterusnya menggunakan satuan tersebut sampai dengan selesai pengukuran.

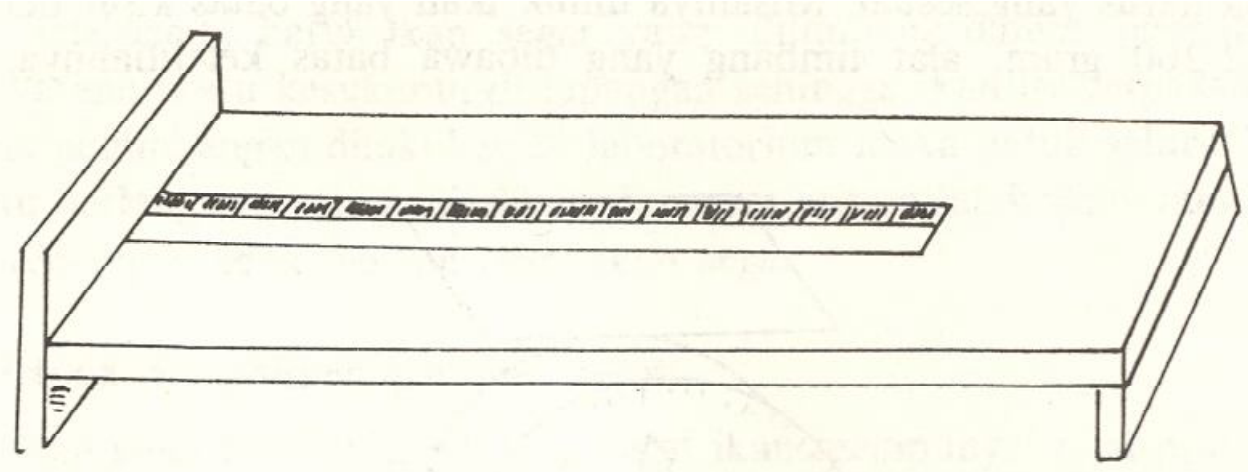

Gambar 1. Mistar atau papan ukur. 


\section{Timbangan Duduk}

Timbangan piringan (Gambar 2) mempunyai berbagai kapasitas 1,5 dan $10 \mathrm{~kg}$ dengan ketelitian $0,1 \mathrm{~g}$. Timbangan tersebut sering digunakan pada saat penimbangan contoh ikan di lapangan. Kelebihan menggunakan timbangan tersebut adalah dapat dilakukan lebih cepat dan lebih teliti serta dapat mengurangi pengaruh dari angin dan goyangan. Sedangkan kekurangan adalah kapasitas terbatas serta bila ikan hidup sering meloncat (Effendie, 1975). Ikan yang ditimbang serta piring timbangan harus dalam keadaaan bersih dari kotoran. Selain itu, timbangan duduk dapat juga digunakan timbangan triple beam yang digunakan pada saat pelaksanaan penimbangan di laboratorium.

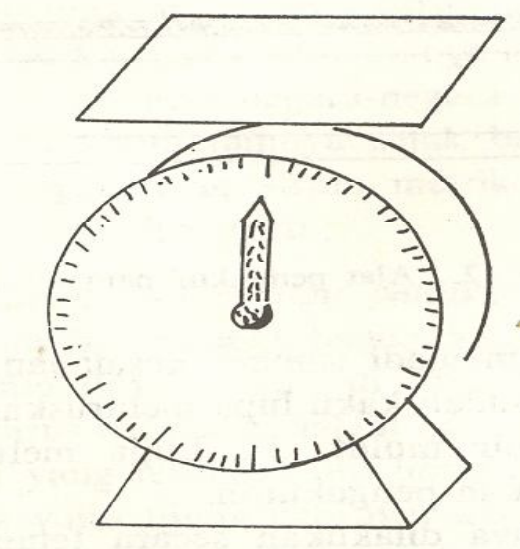

Gambar 2. Timbangan piringan.

\section{Cara Kerja}

Pengukuran panjang baik di lapangan maupun di labolatorium dilakukan dengan prosedur sebagai berikut:

1. Siapkan ikan contoh yang sudah dibersihkan dan papan ukur.
2. Ambil ikan dan letakkan ikan di atas papan ukur.

3. Kemudian ukur panjang total dan panjang standar (Gambar 3).

4. Catat hasil pengukuran dan pisahkan ikan yang sudah diukur dengan yang belum diukur.

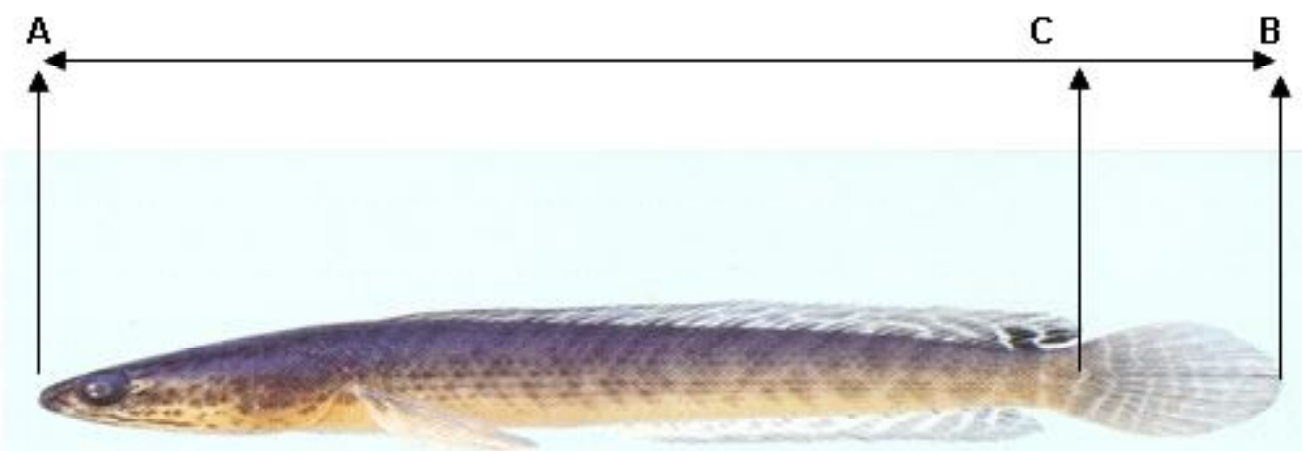

Gambar 3. Ukuran panjang total dan panjang standar ikan gabus.

Keterangan: $\mathrm{A}-\mathrm{B}=$ panjang total $(\mathrm{cm}) ; \mathrm{A}-\mathrm{C}=$ panjang standar $(\mathrm{cm})$

Penimbangan ikan baik di lapangan maupun laboratorium sebagai berikut:

1. Siapkan ikan contoh dan timbangan yang sudah dibersihkan.
2. Ambil ikan dan letakkan dipiring timbangan.

3. Catat hasil yang didapat dalam penimbangan tersebut. 
Tabel 1. Hasil pengukuran panjang dan bobot ikan gabus daerah Sungai Putak dan Arisan Belida

\begin{tabular}{cccc}
\hline No. & $\begin{array}{c}\text { Panjang total } \\
(\mathbf{c m})\end{array}$ & $\begin{array}{c}\text { Panjang standar } \\
(\mathbf{c m})\end{array}$ & $\begin{array}{c}\text { Bobot ikan } \\
(\mathbf{g})\end{array}$ \\
\hline 1 & 32 & 26,7 & 334,3 \\
2 & 21,1 & 16,7 & 71,8 \\
3 & 32,5 & 26,1 & 288,8 \\
4 & 19,3 & 15,2 & 60 \\
5 & 18,5 & 15 & 45,4 \\
6 & 32,4 & 26,3 & 317,4 \\
7 & 27,4 & 22 & 204,5 \\
8 & 17,2 & 14,2 & 37,2 \\
9 & 23 & 18,8 & 97,4 \\
10 & 15,7 & 12,4 & 28,5 \\
11 & 16 & 12,8 & 35,8 \\
12 & 17,1 & 13,6 & 37,8 \\
13 & 15,2 & 12,3 & 31,9 \\
\hline
\end{tabular}

Tabel 2. Hasil pengukuran panjang dan bobot ikan gabus daerah lebak Pasunde

\begin{tabular}{cccc}
\hline No. & $\begin{array}{c}\text { Panjang total } \\
(\mathbf{c m})\end{array}$ & $\begin{array}{c}\text { Panjang standar } \\
(\mathbf{c m})\end{array}$ & $\begin{array}{c}\text { Bobot ikan } \\
(\mathbf{g})\end{array}$ \\
\hline 1 & 27 & 23,1 & 159,2 \\
2 & 31 & 25,6 & 299,4 \\
3 & 36,2 & 30,2 & 485,2 \\
4 & 27,8 & 23 & 195,8 \\
5 & 23,1 & 19 & 116,7 \\
6 & 33,6 & 27,8 & 374,8 \\
7 & 24 & 20,3 & 141,3 \\
8 & 25,1 & 21,3 & 152,1 \\
9 & 27,2 & 22,6 & 182,1 \\
10 & 27,2 & 22,6 & 182,6 \\
11 & 21,7 & 27,6 & 188,3 \\
12 & 31,4 & 26,1 & 87,4 \\
13 & 37,7 & 30,3 & 289,2 \\
\hline
\end{tabular}

Pengukuran panjang dan bobot ikan gabus ini dilakukan pada lokasi yaitu daerah Sungai Putak dan Arisan Belida serta daerah lebak Pasunde karena daerah tersebut mengalir Sungai Musi. Hasil pengukuran panjang dan bobot ikan gabus tercantum pada Tabel 1 dan 2, masing-masing untuk Sungai Putak, Arisan Belida dan lebak Pasunde. Panjang total merupakan panjang ikan yang diukur dari ujung kepala sampai dengan ujung ekor. Sedangkan panjang standar adalah panjang ikan yang diukur dari ujung kepala sampai dengan pangkal ekor. Bobot ikan merupakan bobot keseluruhan sebelum dilakukan pembedahan.

\section{KESIMPULAN}

Pengukuran panjang dan bobot ikan sangat penting. Hubungan pengukuran panjang dan bobot ikan sangat menentukan pola pertumbuhan dan faktor kondisi. Sedangkan data panjang ataupun data bobot sangat berguna untuk mengetahui model 
pertumbuhan. Model pertumbuhan meliputi umur dan ukuran ikan yang ada di alam.

\section{UCAPAN TERIMA KASIH}

Penulis mengucapkan terima kasih pada Dra. Niam Muflikah dan Dr. Ir. H. Mas Tri Djoko Sunarno, M.S. sebagai peneliti dan Muhtarul Abidin sebagai teknisi yang telah membantu dalam penulisan makalah ini.

\section{DAFTAR PUSTAKA}

Anonimus, 1987. Kapupaten Musi Banyuasin dalam angka Bappeda TK II. Kabupaten Musi Banyuasin, Sumatera Selatan. Sekayu, Sumatera Selatan. 337 hal.
Effendie, M. Ichsan. 1975. Metode biologi perikanan. Fakultas Perikanan. Institut Pertanian Bogor. Bogor.

Gaffar, A. K. 2003. Upaya pelestraian dan pengembangan plasma nutfah ikan di perairan umum Sumatera Selatan. Makalah Pembekalan Pengurus Komisi Daerah Plasma Nutfah Propinsi Sumatera Selatan. Palembang.

Makmur. S., M. F. Raharjo, \& S. Sukimin. 2003. Makanan ikan gabus (Channa sriata Block) di daerah banjiran Sungai Musi, Sumatera Selatan. Prosiding Seminar Nasional Perikanan Indonesia. Sekolah Tinggi Perikanan. Jakarta.

Wibowo, A. \& M. T. D. Sunarno. 2005. Kelimpahan ikan dan suhu perairan Sungai Musi. Warta Penelitian Perikanan Indonesia. Badan Riset Kelautan dan Perikanan. Jakarta. 